\title{
Comparison of SWL and RIRS in lower calyceal stones
}

\author{
Basri Cakiroglu ${ }^{1, *}$, Tuncay Tas ${ }^{2}$, Seyit Erkan Eyyupoglu ${ }^{3}$, Aydin Ismet Hazar², \\ M. Bahadir Can Balci ${ }^{2}$, Suleyman Hilmi Aksoy ${ }^{4}$, Bekir Sami Uyanik ${ }^{5}$ \\ ${ }^{1}$ Hisar Intercontinental Hospital, Department of Urology, 34768 Umraniye, Istanbul, Turkey \\ ${ }^{2}$ Taksim Training and Research Hospital, Department of Urology, 34433 Taksim, Istanbul, Turkey \\ ${ }^{3}$ Sabuncuoglu Serefettin Training and Research Hospital, Department of Urology, 05200 Amasya, Turkey \\ ${ }^{4}$ Hisar Intercontinental Hospital, Department of Radiology, 34768 Umraniye, Istanbul,Turkey \\ ${ }^{5}$ Hisar Intercontinental Hospital, Department of Clinical Biochemistry, 34768 Umraniye, Istanbul, Turkey
}

\section{Email address:}

drbasri@gmail.com(B. Cakiroglu), drtastuncay@gmail.com(T. Tas), seeseesee@hotmail.com(S. E. Eyyupoglu), mdhazar@hotmail.com(A. I. Hazar), drbalci@yahoo.com(M. B. C.Balci), saksoy@hisarhospital.com(S. H. Aksoy), bsuyanik@hisarhospital.com (B. S. Uyanik)

\section{To cite this article:}

Basri Cakiroglu, Tuncay Tas, Seyit Erkan Eyyupoglu, Aydin Ismet Hazar, M. Bahadir Can Balci, Suleyman Hilmi Aksoy, Bekir Sami Uyanik. Comparison of SWL and RIRS in Lower Calyceal Stones. Science Journal of Clinical Medicine.

Vol. 2, No. 6, 2013, pp. 166-170. doi: 10.11648/j.sjcm.20130206.14

\begin{abstract}
Background: The efficacy of extracorporeal shock wave lithotripsy(SWL) in kidney stones in the lower calices was compared using retrograde intrarenal surgery(RIRS). Methodology And Materials: Between January 2008 and May 2011, 64 patients (40 male and 24 female) undergoing SWL and 60 patients ( 38 male 22 female) undergoing flexible URS were analyzed retrospectively, and success rates were compared. Using the Storz Medical Modulith SLK, patients underwent the SWL process prior to the induction of anesthesia. On the other hand, the $8 \mathrm{f} \mathrm{Storz} \mathrm{flex} \mathrm{X2} \mathrm{flexible} \mathrm{URS} \mathrm{was}$ used for URS after general anesthesia and RIRS. During the RIRS process, stones were crushed using the $0.2 \mathrm{~mm}$ diameter holmium: YAG laser probe, and stone fragments larger than $2 \mathrm{~mm}$ were extracted. In some cases, double J or ureteral catheters were placed in the ureter. Results: In the 64 patients undergoing SWL with lower caliceal stones, the following ranges were noted: stone diameter: 6-35 mm (mean $15.9 \mathrm{~mm}$ ), age: 16-72 years (mean, sessions required: 1-4 sessions (mean: 1.6), the number of shots: 1000-7650 (mean: 4124.6), fire intensity: 25-75 (mean: 60). Ten percent of patients required analgesia, and the success rate of the procedure was $87.5 \%$. Hematuria occurred in $65 \%$ of patients as a minor complication and in $2 \%$,streinstrasse occurred as a major complication. Inpatients undergoing RIRS, the following ranges were noted: stones size: 7-30 mm in diameter (average $15.2 \mathrm{~mm}$ ), age: 21-60 years (mean 39.75), duration of operation: 3085 minutes(mean: 48.8 minutes), respectively. An access sheath was used in all 32 patients. Balloon dilation was performed in 8 patients with distal ureteral stenosis, and a double $\mathrm{J}$ catheter was placed in 2 patients because of stenosis in the upper ureter and four weeks later, the stones were treated with fURS. Patients were discharged on an average of 1.2 days (1-3 days). A ureteral laceration was noted in $30 \%$ of patients while $75 \%$ of patients had hematuria. Partial ureteral avulsion occurred in one patient with an overall success rate of $96.4 \%$. Conclusions: During the treatment of lower caliceal stones, the success and complication rate of RIRS is higher than SWL.
\end{abstract}

Keywords: Lower Calyceal Stones, SWL, RIRS, Holmium YAG Laser, Laser Lithotripsy

\section{Introduction}

The lower calyx has a different significance in the treatment of kidney stones due to its anatomic properties. Undoubtedly, the only option in treatment of lower caliceal stones used to be open surgery prior to the advent of endourologic technology. After the successful use of shock wave lithotripsy (SWL) and percutaneous nephrolithotripsy
(PNL) in the treatment of kidney stones in the early 1980s, treatment options for lower calyx stones have become a serious matter of debate (1). Flexible ureterorenoscopy (fURS) was first reported as a prototype by Marshall in 1964 (2). The development of flexible, thinner fURS with a high image quality and a wider operating channel has facilitated easier access to the caliceal system. The efficacy of SWL in the treatment of lower calyx stones has been questioned in recent years (3). When the lower success rate 
of SWL in treating lower calyx stones and the morbidity of PNL are considered, RIRS has been applied more frequently in recent years. RIRC has a success rate that is equivalent to minimal morbidity and SWL at lower calyx stones, which are less than one $\mathrm{cm}$. At lower calyx stones up to $2 \mathrm{~cm}$, a higher success rate than SWL is noted (4).

\section{Materials and Methods}

We retrospectively reviewed the medical records and radiologic films of 124 patients who underwent RIRS and SWL for the treatment of renal calculi from

January 2008 and May 2011. Preoperative imaging studies, including abdominal plain x-rays, intravenous pyelograms, or abdominal computed tomography (CT), were evaluated for characteristics of renal stones, including laterality, location, number, size, and radio-opacity. Patients undergoing RIRS were analyzed retrospectively, and the success rates of events were compared. The Storz Medical Modulith SLK was used to perform SWL on any patient prior to analgesia and anesthesia procedure. However, URS was performed with a $8 \mathrm{f}$ Storz flex $\mathrm{x} 2$ flexible URS, with all surgery being performed with the patient in the dorsal lithotomy position under general anesthesia. A safety hydrophilic guide wire was positioned in the upper urinary tract using an 8/8.9 Fr. semi-rigid ureteroscopy, and retrograde pyelography by fluoroscopy with contrast dye was performed to identify urinary stones and delineate urinary tract anatomy. Except in cases of renal stones, which could be accessed byuse of a semi-rigid ureteroscopy only, a flexible ureteroscopy access sheath was placed based on the surgeon's preference. During the RIRS process, stone fragmentation was performed with a Holmium-YAG laser using a 200 or $365 \mu$ fiber. Fragmented stones were extracted with a stone basket or irrigation. In some cases, double $\mathrm{J}$ or ureteral catheters were placed in the ureter. A double $\mathrm{J}$ ureteral stent was routinely placed at the end of each procedure in all patients and was removed 2 weeks later on an outpatient basis.

The diameters of stones were between 7-20 mm (average $12 \mathrm{~mm})$. SWL was contraindicated in pregnant patients, patients with active urinary tract infections, and in patients with a serious deterioration of kidney function. SWL and RIRS were indicated in patients with existing symptoms (pain, urinary obstruction), stones bigger than $6 \mathrm{~mm}$ with inability to pass urine. Drugs such as aspirin, warfarine natrium and clopidogrel were not discontinued. Instead, these patients received shocks with number of less than 1500 and intensity less than 50. The diagnosis was confirmed with ultrasound, IVP(intravenous pyelogram) and $\mathrm{CT}$ scan. CBC, full blood biochemistry, complete urinalysis and urine cultures were obtained prior to SWL and RIRS. No, spinal or epidural anaesthesia, sedation or narcotic analgesics were used. Intramuscular diclophenac sodium was administered when the pain score was 5 out of 10 or more. In cases of persistent pain, Tramadol $\mathrm{HCl} 2 \mathrm{mg}$ $/ \mathrm{kg}$ was administered intravenously. In order to facilitate efficiency and safe application, ultrasonic focusing was used in this device which has abilities of both, ultrasonic and $\mathrm{x}$-ray focusing. Patients were then rescheduled for follow upat the $10^{\text {th }}, 20^{\text {th }}$ and $30^{\text {th }}$ days, and the $3^{\text {rd }}$ month after the procedure. At the follow up visits, all patients underwent both urinary x-rays and ultrasound. An interval period of 10 days between sequences was scheduled. All patients received recommendations regarding prescription drugs (analgesics, antiseptics), fluid intake, necessary bed position and sports activities were also recommended.

\section{Results}

In the 64 patients undergoing SWL with lower caliceal stones, the stone diameter was 6-35 $\mathrm{mm}$ (mean $15.9 \mathrm{~mm}$ ), the patient ages ranged from 16-72 years (mean 44.9), the total number of sessions required was 1-4 (mean: 1.6), the number of shots was 1000-7650 (mean: 4124.6) and the fire intensity was 25-75 (mean: 60). Ten percent of patients required analgesia and the success rate of the procedure was $87.5 \%$.Hematuria occurred in $65 \%$ as a minor complication and in $2 \%$, streinstrasse occurred as a major complication. Of these patients, 36 had a right kidney stone and underwent SWL in the prone position. The rest had a left kidney stone and 15 patients without a superimposed stone at the 12th ribunder went the procedure in the prone position. Five patients with the above-mentioned superimposition underwent the procedure in a one-sided prone position, and 10 patients underwent the procedure in the supine position. A1-4 sequence of SWL (average 2) applied to all cases. The number of shocks for every sequence was 1000-7650 (average 4124.6), and the intensity of shocks was between $45-75 \mathrm{kV}$. (average 60).On CT and US after 3 months in all patients (64 patients, who underwent SWL and 3 patients who underwent RIRS first without success and then underwent SWL), a residual stone was detected in 11 patients $(16.4 \%)$. Thus, the total success rate was determined to be $83.5 \%$.

Inpatients undergoing RIRS, the stones were between 7$30 \mathrm{~mm}$ in diameter (average $15.2 \mathrm{~mm}$ ), the patient ages ranged from 21-60 years (mean 39.75), the duration of the operation was an average of 48.8 minutes (30-85 minutes) respectively. An access sheath was used in 32 patients, and balloon dilation was performed in 8 patients with distal ureteral stenosis. A double $\mathrm{J}$ catheter was placed in 7 patients because of stenosis in the upper ureter, and four weeks later, the stones were treated in 4 patients who underwent RIRS and in 3 patients who underwent SWL. Patients were discharged on an average of 1.2 days (1-3 days). In $30 \%(18)$ of patients, a ureteral laceration was noted, and in $75 \%(45)$ of patients, hematuria occurred as minor complication. Partial ureteral avulsion occurred in one patient. Thus the overall success rate was $96.4 \%$. A double $\mathrm{J}$ catheter was placed in 15 patients, and a ureteral catheter was placed in 38 patients. . Three of 22 patients in whom a double $\mathrm{J}$ catheter was placed, experienced significant catheter-related pain. Follow up, USG and CT of 
patients 3 months following the RIRS showed the presence of a residual stone in 6 patients $(10 \%)$.

\section{Discussion}

SWL is a remarkable advancement in the treatment of urinary stones and has been regarded as the standard treatment for most patients since then. It is a very effective treatment with a $90 \%$-success-rate in the extraction of renal pelvis-placed stones. However, the lower success rate of SWL in removing lower calyceal stones requires that alternative strategies be considered for those stones.

While the 2012 EAU guideline proposes that SWL be the first option for the treatment of middle calyx, upper calyx and renal pelvis stones up to $2 \mathrm{~cm}$ in size, it evaluates the treatment of lower calyx stones and proposes the critical stone size as below $1.5 \mathrm{~cm}$ for SWL, unlike other renal stones.

Furthermore, in presence of pregnancy, bleeding diathesis, aortic or renal arterial aneurysm, close to the region treated and in uncontrollable urinary infections, SWL is contraindicated. Additionally, clinical factors (body mass index, skin-stone distance) and patient choice play a significant part in determining the treatment. After fURS and Laser energy have been discovered, a new breakthrough has been made in treatment of kidney stones(5). On one hand, RIRS devices are made such that they have a smaller outside diameter $(6,75-9$ Fr) and a wider operating channel $(3,6-4$ Fr) such that more dual deflection can be obtained. On the other hand, the access cover, holders, expanders, guide wires, and catheters have evolved in compliance with those devices (6). The Holmium YAG laser, which has been in fashion in endoscopic stone surgery since the early 1990s, has a 2100 $\mathrm{nm}$-wavelength and its tissue penetration is $0.4 \mathrm{~mm}$. The energy is transmitted through quartz fibers; it fragments the stone via a photo thermal effect by turning into thermal energy at the surface of the stone at a higher dose and frequency $(15 \mathrm{~W}-10 \mathrm{~Hz})$ while cutting the stone at lower power and frequency (6-9).

The definite indications for RIRS include a bleeding diathesis, anatomic disorders, obesity and stones for which PCNL, SWL and medical treatment are ineffective.

The operation-specific complications include in or complications (approximately 5\%-13.5\%), such as inability to reach the stone, a residual stone, fever, pain, urinary infection, temporary hematuria, acute urinary retention, ureteral and pelvicaliceal epithelial abrasion, minimal extravasation and major complications (approximately 5\%) such as obstructive pyelonephritis, streinstrasse, subcapsular hematoma, perforation, fornix tear, urinoma, avulsion $(0.06 \%-0.45 \%)$, bleeding requiring transfusion, bacteremia, urosepsis. Through technological progress and diameter declines on RIRS, complications like avulsion have decreased and dropped to $1.5 \%(10-13)$. The probability of a ureteral stricture may be decreased by placing a double $-\mathrm{j}$ stent(14).Today, more than $90 \%$ of patients are discharged within the first 24 hours after treatment (10). The rate of patients who stay in the hospital is $4.9 \%$ and is nearly equal to the complication rate(7). In a study comparing PCNL and RIRS, the duration of stay at a hospital is $60 \pm 28.8$ and $26.5 \pm 10.6$ hours (15).

When the success rates of lower calyx stones in the literature are considered, since there is no standardization in terms of stone load, fragmentation, SFR, duration, diagnostic tool of choice, and definition, the results of the studies cannot be compared with each other. In general, the results are a bit higher than SWL, and a bit lower than in the other renal locations. In a well-organized study (9), which is primary for the RIRS treatment of lower calyx stones, single-session fURS fragmentation results in3 groups of stones, classified as $<10,10-20$ and $>20 \mathrm{~mm}$ were $94 \%, 95 \%$ and $45 \%$ respectively. When a $2^{\text {nd }}$ session treatment was applied to the last group, the fragmentation rate reached $82 \%$ and became $91 \%$ over all the reachable ones; when the non-stone (stonelessness) rates in $3^{\text {rd }}$ month were examined, it was $82 \%, 71 \%$ and $65 \%(16)$. In a study (16), in which the anatomically different properties of the lower calyx group including infundibular length, and its subpolar anatomic properties were discussed in 1998 are emphasized $(17,18)$. The fact that the infundibulopelvic angle is bigger than 70 degree, its length is bigger than 3 $\mathrm{cm}$ and its width is smaller than $5 \mathrm{~mm}$ are all important parameters for SWL. However, even if fURS is said to affect treatment, the paper mentions that this does not reach statistically significant difference in terms of results $(17,18)$. It is said in a new study that unlike both these groups, the angle has a significant effect on the non-stone (stonefree) rates in fURS, and that the effect of other parameters is identical (19). In a study by El-Nahas in 2012, 37 SWL and 62 fURS patients are compared in terms of treatment of subpolar stones with $10-20 \mathrm{~mm}$ diameter. The non-stone (stonefree) rates were found to be $67.7 \%$ and $86.5 \%$ respectively, and the difference was statistically significant (9).In this study, the patients whose stones could not be broken through SWL or fURS were treated with PCNL, and patients who underwent SWL, with clinically significant residual stones were treated with fURS, and patients who underwent fURS were treated with SWL. Another study compared PCNL and fURS in terms of treatment of $15-20$ $\mathrm{mm}$ lower calyx stones and found the success in a singlesession treatment to be $98.2 \%$ and $89.2 \%$ respectively; this rate increased after repeating rigid and flexible treatments/interventions in 2 patients and was proposed as an alternative to PCNL in some cases with accept able morbidity rates (20).

When the literature data are reviewed, in lower calyx stones, the success of fURS is $82-100 \%$ in stones under 1 $\mathrm{cm}, 62-87.5 \%$ in $1-2 \mathrm{~cm}$ stones, while the success rate of SWL success is $21-80 \%$ on the whole, is $59-60 \%$ in the $>1 \mathrm{~cm}$ group and is $60-80 \%$ in $<1 \mathrm{~cm}$ group (21-26). However, this success rate decreases as the stone diameter increases; thus it seems nearly impossible to obtain stonelessness through a single-session in stones bigger than 
$3 \mathrm{~cm}$ (27). Hence, a 2-cm diameter can be accepted as the limit for fURS (27).

The success rates in literature, as well as the lower SWL success rate high PCNL morbidity, show that URS can be a significant alternative in the group with $1-2 \mathrm{~cm}$ stones. Prospective studies may be designed on whether lower calyx stones smaller than $1 \mathrm{~cm}$ which do not present clinically or disrupt the kidney functions need to be treated.

In this current study, the results of 2 different methods in treating lower calyx stones for SWL and fURS are examined. Treatment options for lower calyx stones and their results are discussed. The success of SWL at stones of this group is lower than in the other renal locations due to the fact that the fragmented parts are not thrown easily through gravity-directed movement. In unfavorable caliceal anatomic cases, the rate of stonelessness following fURS is lower. Stone load is another important factor which affects the success of fURS negatively.

In our study, as of January of 2008, the 41-month patient records, pre-treatment and post-treatment images and process/transaction notes are recorded separately for each patient. As is the case with other stone treatments, we evaluate the success of the method in terms of. We accept the success size as $4 \mathrm{~mm}$ for SWL and $2 \mathrm{~mm}$ for fURS, depending on the general tendency in the literature. There is no significant difference between patient groups and numbers. The groups have characteristics similar to each other. Although the number of patients included is not sufficient, results are examined in terms of the average stone load due to the fact that statistical significance cannot be achieved when the results are separated according to the stone groups. In this regard, there is no statistically difference when the stone load and distribution of groups are compared. However, in terms of results, the rate of SWL stonefree (27.) in lower calyx stones with an average stone diameter of $15.9 \mathrm{~mm}$ is lower than the fURS group $(96.4 \%)$ with an average stone diameter of $15.2 \mathrm{~mm}$. The success of SWL is thus higher than in the literature. We attribute this to the fact that devices with limited equipment are used in older studies in the literature. In newer studies, SWL results are higher due to the use of devices with a high focal distance and focusing capacity, with the dual imaging system.

In conclusion, the duration of stay at the hospital, the usage rate of access covers, the rate of placement of a double $\mathrm{J}$ catheter and its indications are in compliance with the literature. Minor complication rates may have been lower if we did not account for temporary hematuria and minimal abrasions also as complications. Except 1 avulsion, no major complications were noted. Through advancement of the technique, tools and experience, both SWL and fURS are considered as treatment options for lower calyx stones which can be used prior to PCNL, the morbidity and operation duration of which is greater.

\section{References}

[1] Göğüş Ç, Böbrek Alt Kalis Taşlarında Tedavi.Turkiye Klinikleri J.Med.Sci.2006; 2(4):10-12

[2] Marshall V: Fiberoptics in Urology. J Urol 1964; 160:110-4

[3] Stav K, Cooper A, Zisman A, Leibovici D, Lindner A, Siegel YI. Retrograde intrarenal lithotripsy outcome after failure of shock wave lithotripsy. J Urol;2003; 170:2198-201,

[4] Pearle MS, Lingeman JE, Leveillee R, Kuo R, Preminger GM, Nadler RB, et al. Prospective, randomized trial comparing shock wave lithotripsy and ureteroscopy for lower pole caliceal calculi $1 \mathrm{~cm}$ or less. J Urol;2005; 173:2005-9, 2005

[5] Johnston WK $3^{\text {rd }}$, Low RK, Das S. The evolution and progress of ureteroscopy. UrolClin North Am 2004;31,5-13

[6] Bryniarski P, Paradysz A, Zyczkowski M, Kupilas A, Nowakowski K, Bogacki R. A Randomized Controlled Study to Analyze the Safety and Efficacy of Percutaneous Nephrolithotripsy and Retrograde Intrarenal Surgery in the Management of Renal Stones More Than $2 \mathrm{~cm}$ in Diameter J Endourol. 2012 Jan; Volume 26, Number 1, Pp. 52-57

[7] Wiesenthal JD, Ghiculete D, D'A. Honey RJ, Chir B. Pace KT. A Comparison of Treatment Modalities for Renal Calculi Between 100 and 300mm2:Are Shockwave Lithotripsy, Ureteroscopy,and Percutaneous NephrolithotomyEquivalent?JEndourol. 2011 Mar; Volume 25, Number 3, Pp. 481-485

[8] Me'ndez Probst CE, Denstedt JD, Razvi H. Preoperative Indications for Percutaneous Nephrolithotripsy in 2009.J Endourol.2009 Oct;Volume 23, Number 10, Pp. 1557-1561

[9] El-Nahas AR, Ibrahim HM, Youssef RF, Sheir KZ. Flexible ureterorenoscopy versus extracorporeal shock wave lithotripsy for treatment of lower pole stones of 10-20 mm.BJU Int. 2012 Sep;110(6):898-902

[10] Hyams ES, Munver R, Bird VG, Uberoi J, Shah O. Flexible Ureterorenoscopy and Holmium Laser Lithotripsy for the Management of Renal Stone Burdens That Measure 2 to 3 $\mathrm{cm}$ : A Multi-Institutional Experience. Journal of Endourology 2010 Oct; Volume 24, Number 10, Pp. 15831588 .

[11] Aboumarzouk OM, Monga M, Kata SG, Traxer O, Soman BK. Flexible Ureteroscopy and Laser Lithotripsy for Stones $>$ $2 \mathrm{~cm}$ : A Systematic Review and Meta-Analysis Journal of Endourology.2012 Oct; Volume 26, Number 10, Pp. $1257-$ 1263

[12] Harmon WJ, Sershon PD, Blute ML, et al. Ureteroscopy:Current practice and long-term complications. J Urol.1997;157:28-32.

[13] Ge C, Li Q, Wang L, Jin F, Li Y, Wan J, Lan W et al. Management of Complete Ureteral Avulsion and Literature Review: A Report on Four Cases Journal of Endourology. $2011 \mathrm{Feb} ; 25(2)$ : 323-326

[14] Schoenthaler M, Wilhelm K, Kuehhas FE, Farin E, Bach C et al. Postureteroscopic Lesion Scale: A New Management Modified Organ Injury Scale-Evaluation in 435 Ureteroscopic Patients. Journal of Endourology 2012;26.11, $1425-1430$ 
[15] AkmanT,Binbay M, Ugurlu M, Kaba M, Akcay M, Yazici O et al.Outcomes of Retrograde Intrarenal Surgery Compared with Percutaneous Nephrolithotomy in Elderly Patients with Moderate-Size Kidney Stones: A Matched-Pair Analysis.Journal of Endourology.2012 June; Volume 26, Number 6, Pp. 625-629

[16] Grasso M, Ficazzola M. Retrograde ureteropyeloscopy for lower pole caliceal calculi. J Urol. 1999 Dec;162(6):1904-8

[17] Elbahnasy AM, Shalhav AL, Hoenig DM, Elashry OM, Smith DS, McDougall EM, Clayman RV. Lower caliceal stone clearance after shock wave lithotripsy or ureteroscopy: the impact of lower pole radiographic anatomy.J Urol. 1998 Mar;159(3):676-82

[18] Elbahnasy AM, Clayman RV, Shalhav AL, Hoenig DM, Chandhoke $\mathrm{P}$ et al. Lower-Pole Caliceal Stone Clearance after Shockwave Lithotripsy, Percutaneous Nephrolithotomy, and Flexible Ureteroscopy: Impact of Radiographic Spatial Anatomy. Journal of Endourology 1998;April, Volume 12, Number 2

[19] Resorlu B, Oguz U, Resorlu EB, Oztuna D, Unsal A. The impact of pelvicaliceal anatomy on the success of retrograde intrarenal surgery in patients with lower pole renal stones. Urology. 2012 Jan;79(1):61

[20] Bozkurt OF, Resorlu B, Yildiz Y, et al. Retrograde intrarenal surgery versus percutaneous nephrolithotomy in the management of lower-pole renal stones with a diameter of 15 to 20mm.Journal of Endourology. 2011;25,1131-1135.
[21] Lingeman JE, Siegel YI, Steele B, Nyhuis AW, Woods JR Management of lower pole nephrolithiasis: a critical analysis. J Urol. 1994 Mar;151(3):663-7

[22] Ozgur Tan M, Irkilata L, Sen I, Onaran M, Kupeli B, Karaoglan U, et al. The impact of radiological anatomy in clearance of lower caliceal stones after shock wave lithotripsy. Urol Res. 2007;35.143-7

[23] Ghoneim IA, Ziada AM, Elkatib SE. Predictive factors of lower calyceal stone clearance after Extracorproeal Shockwave Lithotripsy (ESWL): A focus on the infundibulopelvic anatomy. Eur Urol. 2005;48:296-302

[24] Albala DM, Assimos DG, Clayman RV, Denstedt JD, Grasso M. Et al. Lower pole I: a prospective randomized trial of extracorporeal shock wave lithotripsy and percutaneous nephrostolithotomy for lower pole nephrolithiasis-initial results. J Urol. 2001 Dec;166(6):2072-80

[25] Grasso M, Bagley D.Small diameter, actively deflectable, flexible ureteropyeloscopy. J Urol. 1998 Nov; 160(5):164853; discussion 1653-4

[26] Schoenthaler M, Wilhelm K, Katzenwadel A, ArdeltP,Wetterauer $U$ et al. Retrograde Intrarenal Surgery in Treatment of Nephrolithiasis:Is a 100\% Stone-Free Rate Achievable? Journal of Endourology.2012 May; Volume 26, Number 5, Pp. 489-493

[27] Hussain M, Acher P, Penev B, Cynk M. Redefining the Limits of Flexible Ureterorenoscopy.Journal of Endourology 2011 Jan; Volume 25, Number 1, Pp. 45-49 